Chronic Obstructive Pulmonary Diseases: Journal of the COPD Foundation

\author{
Original Research
}

\title{
Impact of Heated Humidified High Flow Air via Nasal Cannula on Respiratory Effort in Patients with Chronic Obstructive Pulmonary Disease
}

\author{
Charles W. Atwood, Jr., MD ${ }^{1,2}$ Sharon Camhi, MD ${ }^{1,2}$ Kathryn C. Little, MA, RN ${ }^{3}$ Colleen Paul, RN, PhD ${ }^{1}$ \\ Hobart Schweikert, MS, RRT ${ }^{1}$ Nicholas J. Macmillan, BGS, RRT, FAARC ${ }^{4}$ Thomas L. Miller, PhD ${ }^{5,6}$
}

\section{Abstract}

Background: High flow nasal cannula therapy (HFNC) has been widely adopted for respiratory distress, and evidence suggests that purging dead space of the upper airway improves gas fractions in the lung. This study tests the hypothesis that HFNC with room air could be as effective as low flow oxygen in chronic obstructive pulmonary disease (COPD).

Methods: Thirty-two COPD patients prescribed 1-2 L/min of oxygen were studied. The conditions tested consisted of a control (CTRL; no therapy), then in random order HFNC and prescribed low flow oxygen (LFO). HFNC was the highest flow tolerated up to $35 \mathrm{~L} / \mathrm{min}$ without supplemental oxygen. Arterial blood gases (ABGs), respiratory rate $(\mathrm{RR})$, heart rate $(\mathrm{HR})$ and tidal volume $\left(\mathrm{V}_{\mathrm{T}}\right)$ were measured at the end of each condition.

Results: Arterial oxygen $\left(\mathrm{PaO}_{2}\right)$ was greater $(p<0.001)$ for LFO than both HFNC and CTRL $(\mathrm{CTRL}=57.4 \pm 6.1$ $\mathrm{mmHg}, \mathrm{HFNC}=58.6 \pm 8.3 \mathrm{mmHg}, \mathrm{LFO}=72.6 \pm 10.2 \mathrm{mmHg})$. HFNC reduced RR by $11 \%(p<0.05)$ from CTRL and LFO (CTRL=20.2 $\pm 3.8 \mathrm{br} / \mathrm{min}, \mathrm{HFNC}=17.9 \pm 3.3 \mathrm{br} / \mathrm{min}, \mathrm{LFO}=20.2 \pm 3.7 \mathrm{br} / \mathrm{min})$ with no differences in $\mathrm{V}_{\mathrm{T}}$. There were no differences between arterial carbon dioxide $\left(\mathrm{PaCO}_{2}\right)(\mathrm{CTRL}=45.5 \pm 4.9 \mathrm{mmHg}, \mathrm{HFNC}=45.0 \pm 5.3 \mathrm{mmHg}$, $\mathrm{LFO}=46.0 \pm 3.9 \mathrm{mmHg})$.

Conclusions: HFNC resulted in a clinically relevant reduction in ventilatory effort with no change in ABG indicating a gas equilibrium effect of purging anatomical dead space.

Clinical Trial Registration: ClinicalTrials.gov ID: NCT00990210

\begin{abstract}
Abbreviations: high flow nasal cannula, HFNC; chronic obstructive pulmonary disease, COPD; control condition, CTRL; low flow oxygen treatment condition, LFO; arterial blood gas analysis, $\mathbf{A B G}$; respiratory rate, $\mathbf{R R}$; heart rate, $\mathbf{H R}$; tidal volume, $\mathbf{V}_{\mathrm{T}}$; carbon dioxide, $\mathbf{C O}_{\mathbf{2}}$; arterial oxygen oxygenation, $\mathrm{PaO}_{2}$; arterial carbon dioxide oxygenation, $\mathrm{PaCO}_{2}$; electrocardiogram, ECG; pulse oximetry, SpO Research Council, mMRC; ventilatory index, VI; arbitrary units, au; forced expiratory volume in 1 second, FEV $\mathbf{1}_{\mathbf{1}}$; forced vital capacity, FVC Funding Support: This study was sponsored by Vapotherm, Inc., Exeter, New Hampshire and conducted at the Veterans Administration Pittsburgh Healthcare System, Pittsburgh, Pennsylvania.

Date of Acceptance: June 8, 2017

Citation: Atwood CW Jr., Camhi S, Little KC, et al. Impact of heated humidified high flow air via nasal cannula on respiratory effort in patients with chronic obstructive pulmonary disease. Chronic Obstr Pulm Dis. 2017;4(4):279-286. doi: https://doi.org/10.15326/ jcopdf.4.4.2016.0169
\end{abstract}

1 Pulmonary Section, Veterans Administration Pittsburgh Healthcare System, Pittsburgh, Pennsylvania

2 Division of Pulmonary, Allergy and Critical Care Medicine, University of Pittsburgh Medical Center, Pittsburgh, Pennsylvania

3 Children's Hospital of Pittsburgh of University of Pittsburgh Medical Center, Pittsburgh, Pennsylvania

\section{The MED Group, Inc., Lubbock, Texas}

5 Vapotherm, Inc., Exeter, New Hampshire

6 Department of Pediatrics, Sydney Kimmel Medical College, Philadelphia, Pennsylvania 


\section{Address correspondence to:}

Charles W. Atwood, Jr., MD

Associate Professor of Medicine

UPMC Montefiore Hospital - NW628

3459 Fifth Avenue

Pittsburgh, PA 15213

Phone: 412-692-2880

Fax: 412-692-2260

Email: Charles.Atwood@va.gov

\section{Keywords:}

high flow nasal cannula; high velocity nasal insufflation; work of breathing; dead space; ventilatory efficiency; oxygenation; ventilation

\section{Introduction}

Heated, humidified high-flow nasal cannula therapy (HFNC) has been widely adopted over the past decade as a therapeutic intervention for patients in respiratory distress. The operating premise is that by approximating a patient's inspiratory flow demand with the flow of respiratory gas from a nasal cannula, the patient will inhale the intended gas mixture without dilution via the entrainment of room air and provide for washout of nasopharyngeal dead space. ${ }^{1}$ However, the technical aspect is that HFNC devices must be able to heat and humidify the delivered gas to at or near body temperature to avoid drying and possible injury to the nasal mucosa ${ }^{2,3}$ and subsequent infections. ${ }^{4}$

The purging of the anatomical dead space contributes to improved fractions of alveolar oxygen and carbon dioxide $\left(\mathrm{CO}_{2}\right)$ independent of any other respiratory support mechanism. In this regard, the end-expiratory gas destined to be re-breathed is replaced with inspiratory gas that is higher in oxygen and lower in $\mathrm{CO}_{2}{ }^{5-7}$ It is plausible that, based on this mechanism, in the absence of a change in breathing pattern, arterial oxygenation $\left(\mathrm{PaO}_{2}\right)$ would improve and arterial $\mathrm{CO}_{2}$ $\left(\mathrm{PaCO}_{2}\right)$ would be reduced.

In previous studies, HFNC has been shown to provide respiratory assistance particularly with respect to dyspnea. ${ }^{8,9}$ Studies in acute care settings have established the superiority of HFNC over conventional means of oxygen therapy, with respect to both oxygenation and ventilation (respiratory rate) outcomes. ${ }^{10,11}$ However, little has been done to manipulate the application of HFNC to distinguish specific mechanisms of action. Whereas animal data show that the dead space flush is a principle mechanism of action, ${ }^{6}$ most human studies have not been mechanistic in nature.

The objective of the current study was to measure the effect of HFNC with room air on blood gas parameters and respiratory patterns in patients with stable chronic obstructive pulmonary disease (COPD) who are currently prescribed continuous use of 1-2 liters of oxygen per minute at rest. We hypothesized that because of nasopharyngeal flush, HFNC with room air would result in the equivalent arterial oxygen tension and hemoglobin saturation $\left(\mathrm{SaO}_{2}\right)$ as with low flow oxygen cannula. Secondary endpoints were related to ventilatory indices such as arterial $\mathrm{CO}_{2}$ tension, breathing pattern and dyspnea.

\section{Methods}

Thirty-two patients were studied under 3 conditions in a repeated-measures experimental design. Participants were first evaluated with neither oxygen nor HFNC support (control; CTRL), and then randomized to receive heated, humidified HFNC with room air (Flowrest ${ }^{\circledR}$, Vapotherm, Inc., Stevensville, Maryland; Figure 1) and their prescribed low flow oxygen therapy (LFO). Supplemental oxygen was not used with HFNC because the study was intended to identify if purging the upper airway between breaths (i.e., replacing expiratory gas that is approximately $16 \%$ oxygen with room air that is $21 \%$ oxygen) can achieve an equivalent increase in alveolar, and subsequently arterial, $\mathrm{PO}_{2}$ compared to low flow oxygen supplementation. Participants were stabilized on room air for 20 min between each arm of the study. The study protocol was approved by the Veterans Administration Pittsburgh Healthcare System's Institutional Review Board.

\section{Patient Selection Criteria}

Inclusion criteria were set such that participants must be greater than 40 years of age, have a greater than 10 pack years smoking history for cigarettes, carry a diagnosis of COPD, and have been prescribed continuous oxygen at 1 to $2 \mathrm{~L} / \mathrm{min}$ at rest.

Exclusion criteria included the following: COPD exacerbation in the previous 2 months, abnormal Allen's test, an unstable comorbidity, or women who are pregnant, have not been through menopause (either natural or surgical) or are not using birth control.

\section{Study Procedures}

After obtaining informed consent participants were enrolled for an approximately 3-hour session in the 


\section{Figure 1. Flowrest ${ }^{(\mathbb{B}}$ Homecare Device (A) with Nasal Cannula (B)}

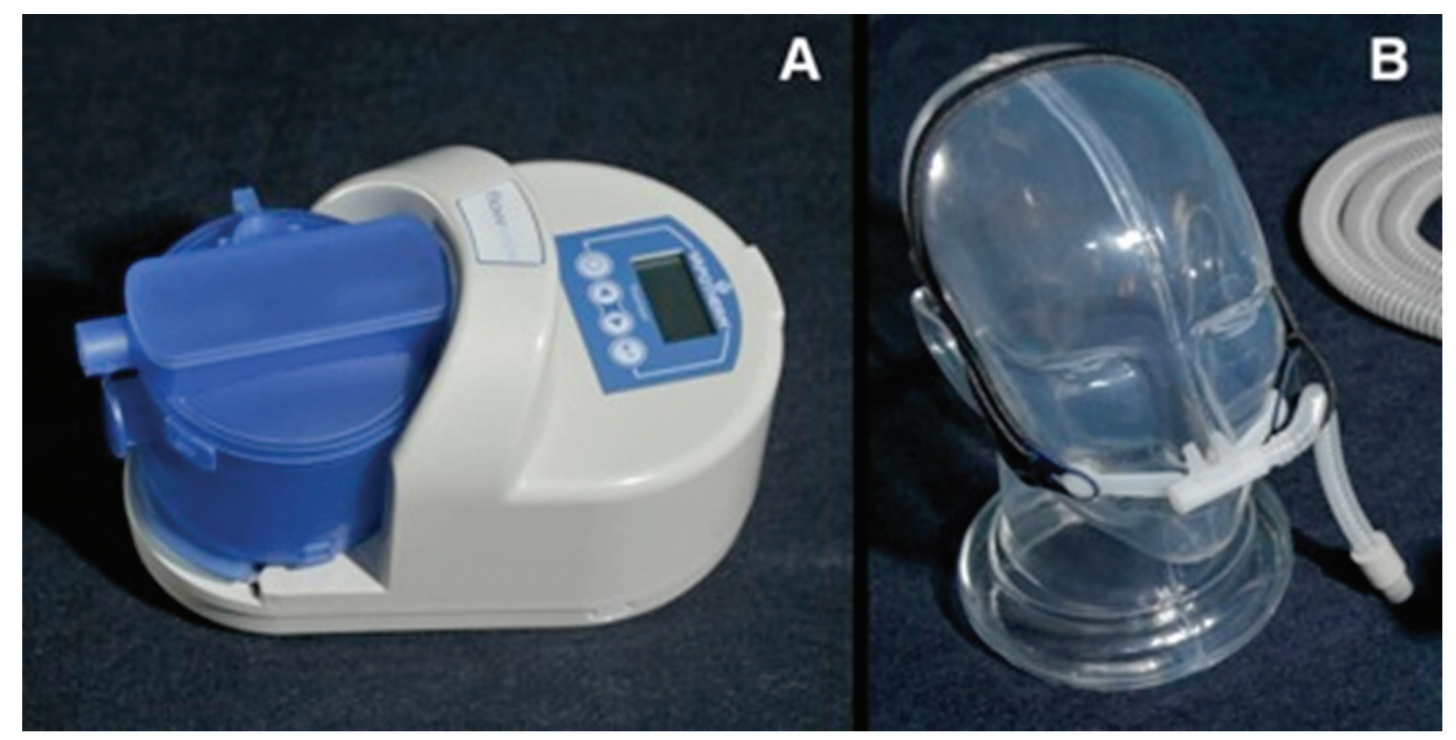

The Flowrest (Vapotherm, Inc., Stevensville, Maryland) delivers conditioned breathing gases through an open system nasal cannula interface at flow rates from 15 to $35 \mathrm{~L} / \mathrm{min}\left(5 \mathrm{~L} / \mathrm{min}\right.$ increments) at $80 \%-90 \%$ relative humidity and temperatures between $31^{\circ}-38^{\circ} \mathrm{C}$. The cannula is attached to the device by way of a warm-air-jacketed delivery tube to eliminate rainout and minimize temperature loss from the conditioned breathing gas.

sleep disorders laboratory. As a first step, all participants completed baseline spirometry using the EasyOne portable spirometer (Niche Medical, Sydney, Australia) to provide a lung function profile for each patient. Following spirometry, participants were fitted with monitoring equipment including respiratory inductive plethysmography belts, electrocardiogram (ECG) leads and pulse oximetry probes (Viasys sleep data acquisition system, CareFusion, San Diego, California). Once connected, and prior to the initiation of testing, the dyspnea scales were explained to the participant so that perceived respiratory effort could be assessed at later points.

Patients were tested at CTRL, and then at HFNC and LFO in random order. During the $30 \mathrm{~min}$ at each condition, heart rate (HR), respiratory rate (RR), change in tidal volume excursion and pulse oximetry $\left(\mathrm{SPO}_{2}\right)$ were monitored continuously and recorded by a modified respiratory montage using the sleep laboratory acquisition system. Additionally, $\mathrm{SPO}_{2}$ was recorded every $5 \mathrm{~min}$ from a bedside monitor. Criteria were set that if the participant's $\mathrm{SPO}_{2}$ fell below $80 \%$ for $15 \mathrm{~min}$ then the study for that participant would be halted. In the last 5 min of each condition an arterial blood sample was drawn from the radial artery by trained staff, and analyzed for respiratory gas composition.

In the last minute of each condition, the Borg and the modified Medical Research Council (mMRC) scales were used to assess perceived dyspnea. The Borg Dyspnea scale is a scale of numbers from 0 to 10 , where 0 is associated with no dyspnea and 10 being maximal dyspnea. The participant is asked how much difficulty their breathing is causing them right now. The mMRC dyspnea scale is a scale from 0 to 4 where each number is associated with a statement about the participant's breathlessness. A score of 0 represents breathlessness only during strenuous activity and 4 represents extreme breathlessness during minimal activity.

For the HFNC treatment condition, participants were started on the therapy at the lowest setting of 15L/ min of nasal cannula flow and increased by $5 \mathrm{~L} / \mathrm{min}$ increments every $5 \mathrm{~min}$ as tolerated by the participant. The objective was to use the greatest flow rate that was comfortable for the patient. For the LFO treatment condition, participants wore conventional oxygen cannulae with their prescribed resting liter flow of oxygen.

$\mathrm{HR}$ and $\mathrm{RR}$ were determined by counting each $\mathrm{R}$ wave from the EKG and each inspiratory waveform signal for a $2 \mathrm{~min}$ period from the first $5 \mathrm{~min}$ of the recording for each condition, and a 2 min period from the last $5 \mathrm{~min}$ of the recording. The reason for having an early versus late group was to examine the possibility of change in cardiac or respiratory parameters from the beginning of the 30 min experimental condition to the end of it.

To determine if there was a change in ventilatory 
efficiency, we calculated a ventilatory index (VI), where $\mathrm{VI}$ is the product of $\mathrm{RR}$ and $\mathrm{PaCO}_{2}$ expressed in arbitrary units (au). The reason for this determination was to allow us to look for changes in ventilatory efficiency of the respiratory system as a whole (i.e., a change in RR without a concomitant change in $\mathrm{CO}_{2}$ elimination, or vice versa). Thus, a change in VI would be indicative of a change in efficiency of the system where a lower value represents greater efficiency.

Relative changes in $\mathrm{V}_{\mathrm{T}}$ were determined from fractional change in amplitude of thoraco-abdominal excursion waveforms using the respiratory inductance plethysmography belts of the data acquisition system. The respiratory inductance plethysmography belts were applied carefully at the beginning of the session and remained unperturbed during data acquisition for the 3 conditions. This allows us to look across conditions for relative changes in respiratory excursion, which would represent changes in $V_{\text {T. }}$. Mean amplitude was measured in arbitrary units (au) from a consecutive 1 min series of $\mathrm{V}_{\text {T }}$ waveforms during the last $5 \mathrm{~min}$ of each condition.

\section{Data Analysis}

The study was powered to detect a $10 \%$ difference in $\mathrm{PaO}_{2}$ between conditions. For each outcome parameter, analyses of variance were performed to identify differences as a function of treatment and treatment by time interactions where applicable. Pearson correlation analyses were performed between change in respiratory parameters with HFNC and baseline spirometry measures to determine if baseline lung function was predictive of treatment results. Significance was accepted at $P<0.05$.

\section{Results}

Participants were all males with a mean age of $69 \pm 9$ yrs with an age range of 55 to 85 years. All participants had clinically confirmed COPD and were prescribed either 1 or 2 liters oxygen at rest. Spirometric testing demonstrated that the participants had significant airflow obstruction wherein the mean forced expiratory volume in 1 second $\left(F E V_{1}\right.$ ) was $1.16 \pm 0.60 \mathrm{~L}$ (range $=0.28$ to $3.06 \mathrm{~L}$ ) and the mean $F E V_{1} / F V C$ ratio was $45.5 \pm 15.7 \%$.

Participant demographic and lung function data are presented in Table 1. No participant experienced an adverse event during the testing procedures. The flow rates used for $\mathrm{HFNC}$ ranged from $15 \mathrm{~L} / \mathrm{min}$ to $35 \mathrm{~L} / \mathrm{min}$.

There was no difference in $H R$ as a function

\section{Table 1. Patient Demographics and Baseline Characteristics}

\begin{tabular}{l|r|r} 
& Mean \pm SD & \multicolumn{1}{c}{ Range } \\
\hline Patient Demographics & & \\
\hline Age (yrs) & $69 \pm 9$ & $55-85$ \\
\hline Body Weight (kg) & $91.0 \pm 29.3$ & $53.6-168.2$ \\
\hline Body Mass Index & $28.4 \pm 7.6$ & $20.3-46.2$ \\
\hline Baseline Lung Function & & \\
\hline FVC (L) & $2.4 \pm 0.7$ & $1.2-4.3$ \\
\hline FEV $_{\mathbf{1}}$ (L) & $1.2 \pm 0.6$ & $0.5-3.1$ \\
\hline FEV $_{\mathbf{1}}$ /FVC (\%) & $45.5 \pm 15.7$ & $0.6-84$ \\
\hline
\end{tabular}

$\mathrm{FVC}=$ forced vital capacity,

$\mathrm{FEV}_{1}=$ forced expiratory volume in 1 second

of treatment (Table 2), nor was there a change in amplitude of VT (CTRL $=24 \pm 16 \mathrm{au}, \mathrm{HFNC}=26 \pm 17 \mathrm{au}$, $\mathrm{LFO}=25 \pm 17 \mathrm{au})$. However, HFNC had a significant impact on $\mathrm{RR}$, reducing frequency by $11 \%$ from both CTRL and LFO ( $p<0.05$; Table 2$)$. RR for CTRL compared to $\mathrm{LFO}$ was not different. $\mathrm{RR}$ and $\mathrm{V}_{\mathrm{T}}$ comparisons are presented in Figure 2.

Oxygenation parameters from the 3 treatment conditions are shown in Figure 3. HFNC was not different from CTRL, where HFNC $\mathrm{PaO}_{2}$ was $58.6 \pm 8.3 \mathrm{mmHg}$ with a $\mathrm{SaO}_{2}$ of $90.4 \pm 3.4 \%$, and CTRL $\mathrm{PaO}_{2}$ that was $57.4 \pm 6.1 \mathrm{mmHg}$ with a $\mathrm{SaO}_{2}$ of $89.8 \pm 3.2 \%$. LFO was greater than both HFNC and CTRL $(p<0.001)$ with a $\mathrm{PaO}_{2}$ that was $72.6 \pm 10.2 \mathrm{mmHg}$ and a $\mathrm{SaO}_{2}$ of $94.0 \pm 3.4 \%$.

There were no significant differences between the groups for $\mathrm{PaCO}_{2}$. The mean values for the CTRL, HFNC, and LFO were $45.5 \pm 4.9 \mathrm{mmHg}, 45.0 \pm 5.3 \mathrm{mmHg}$, and $46.0 \pm 3.9 \mathrm{mmHg}$, respectively. The analysis of VI revealed a significant effect of treatment where ventilation was reduced $12 \%$ with HFNC compared to CTRL and reduced $14 \%$ with HFNC compared to LFO ( $p<0.05$; CTRL $=914 \pm 210 \mathrm{au}, \mathrm{HFNC}=805 \pm 192 \mathrm{au}$, $\mathrm{LFO}=932 \pm 197 \mathrm{au})$. Ventilation indices are presented in Figure 4.

Table 2 shows the data for trending $H R$ and RR over time. For HR there was no impact associated with time on therapy. For RR there was a significant increase over time for the HFNC condition from $16.4 \pm 3.2 \mathrm{br} / \mathrm{min}$ to $17.7 \pm 3.5 \mathrm{br} / \mathrm{min}(p<0.01)$ but not for the control or LFO conditions.

Correlations of patient responsiveness to HFNC (percent decrease in VI from CTRL) with baseline spirometry measures showed a moderate-low level of association for FVC $(\mathrm{r}=0.43 ; p<0.05)$, but non-significant 


\section{Table 2. Comparison of Early Versus Late Data from Each Treatment Condition}

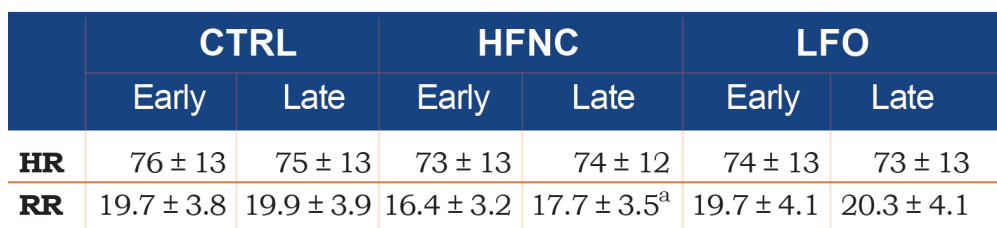

Heart rate (HR; bpm) and respiratory rate (RR; br/min) recorded from the early (first $5 \mathrm{~min}$ ) and late (last $5 \mathrm{~min}$ ) segment of each $30 \mathrm{~min}$ testing phase. There were no time dependent effects at control (CTRL) and low flow oxygen (LFO) conditions; however, with high flow therapy (HFNC) there was a time dependent increase in RR $\left({ }^{\mathrm{a}} p<0.01\right)$.

\section{Figure 2. Breathing Mechanics}
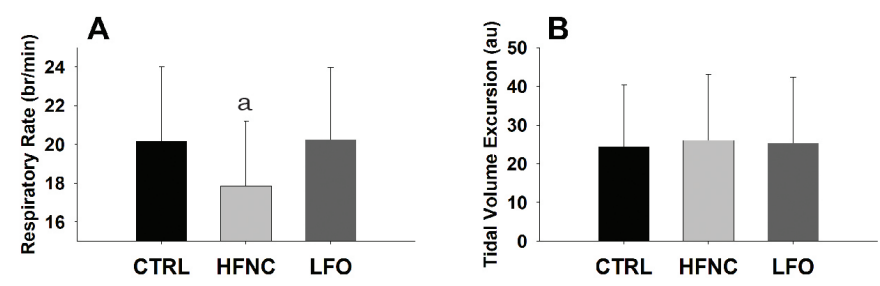

The evaluation of breathing mechanics revealed a treatment effect ( ${ }^{a} P<0.05$ ) for respiratory rate $(\mathrm{A})$, wherein high flow nasal cannula with room air (HFNC) reduced breathing rate compared to control (CTRL) and prescribed supplemental oxygen (LFO). There was no difference detected in amplitude of tidal volume (B) measured in arbitrary units (au) from inductive plethysmography.

\section{Figure 3. Oxygenation Indices}
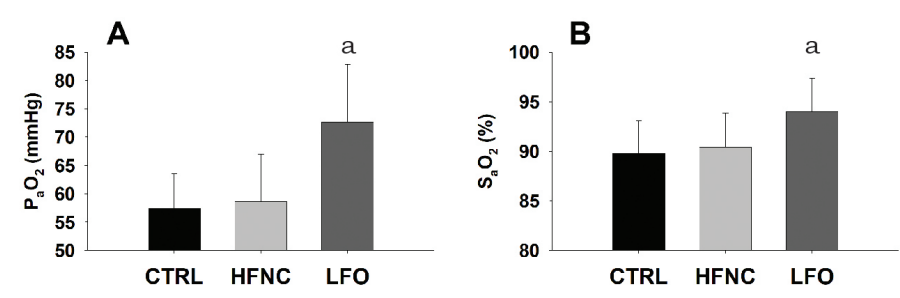

Analyses of oxygenation parameters showed a treatment effect $\left({ }^{\mathrm{a}} P<0.001\right)$ for both arterial oxygen tension (A) as well as arterial hemoglobin saturation (B). In both cases, a patient's prescribed supplemental oxygen (LFO) resulted in increased arterial oxygenation compared to control (CTRL) and high flow nasal cannula with room air (HFNC). CTRL and HFNC were not different.

associations for FEV 1 ( $\mathrm{r}=0.31)$, and $\mathrm{FEV}_{1} / \mathrm{FVC}(\mathrm{r}=0.18)$. The correlation between ventilatory responsiveness to HFNC and FVC is shown in Figure 5.

\section{Discussion}

This is the first study to examine mechanisms of action of HFNC therapy in a clinically important population: elderly patients with advanced COPD. Our findings

\section{Figure 4. Ventilation Indices}
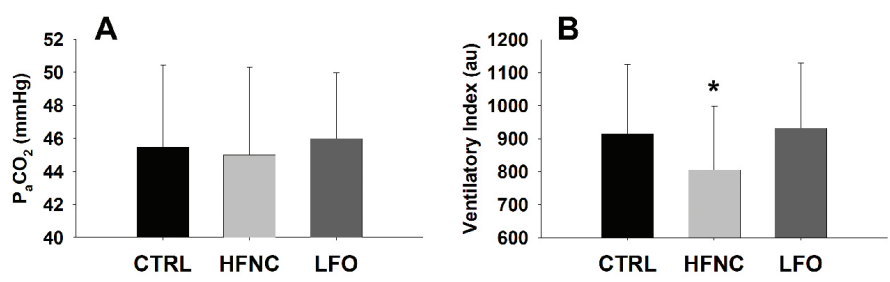

As shown in $\mathrm{A}$, there was no difference between treatments for arterial carbon dioxide tension $\left(\mathrm{PaCO}_{2}\right)$. To assess ventilatory efficiency, a ventilatory index (VI) was calculated (B) as the product of $\mathrm{RR}$ and $\mathrm{PaCO}_{2}$ expressed in arbitrary units (au) where a lower number represents greater efficiency. Analyses of variance across conditions for VI verified that ventilatory effort was reduced for $\operatorname{HFNC}(P<0.05)$ compared to control (CTRL) and prescribed supplemental oxygen (LFO).

\section{Figure 5. Correlation Between Responsiveness to High Flow Nasal Cannula and Lung Function}

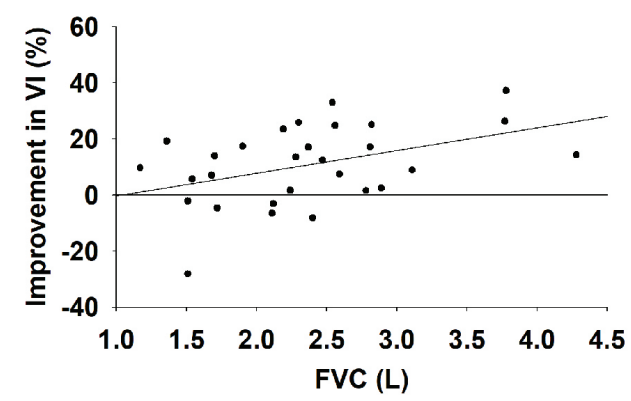

Across all patients, percent improvement in ventilatory index (VI; $\mathrm{PaCO}_{2} \cdot$ respiratory rate) showed a moderate-low correlation $(\mathrm{r}=0.43 ; P<0.05)$ with forced vital capacity (FVC) as an index of lung function. Data points = individual patients. Diagonal line $=$ linear regression.

confirm that HFNC therapy provides a clinically meaningful effect on respiratory parameters as well as showing that the main effect on the respiratory system was a reduction in $R R$ during the acute application of HFNC therapy. The reduction in RR likely equates to a reduction in work of breathing by way of a decreased $\mathrm{RR}$ without a change in $\mathrm{PaCO}_{2}$ or $\mathrm{V}_{\text {T. }}$. Our data supports the concept that HFNC flushes the upper airway dead space of $\mathrm{CO}_{2}$ and thereby allows for inhalation of a lower inspired fraction of $\mathrm{CO}_{2} .{ }^{6,7}$ In this regard, the current study represents the in-human translational component to complement prior animal studies that demonstrated the ventilatory mechanisms of dead space purge by high flow nasal cannula. ${ }^{6}$

Neither arterial oxygen tension nor $\mathrm{SaO}_{2}$ improved from the CTRL condition with HFNC, whereas it did rise significantly with oxygen therapy. However, the most 
remarkable finding of the study was a reduction in $R R$ for HFNC compared to both CTRL and oxygen therapy, which occurred without a concomitant reduction in $\mathrm{PaO}_{2}$. Therefore, it can be inferred that there was in fact an improvement in alveolar fraction of oxygen with HFNC that counterbalanced the reduction in minute ventilation associated with a concomitant improvement in $\mathrm{CO}_{2}$ ventilation.

An interesting aspect regarding the decrease in $\mathrm{RR}$ is the lack of significant change in the $\mathrm{PaCO}_{2}$, which was verified by the calculation of VI. These findings suggest that the reduction in $\mathrm{RR}$ is either offset by an increased $\mathrm{V}_{\mathrm{T}}$ or that effective exhalation of $\mathrm{CO}_{2}$ is increased such that the mixed dead space $\mathrm{CO}_{2}$ fraction is less. The respiratory inductive plethysmography data indicates that there was no change in $\mathrm{V}_{\mathrm{T}}$ excursion. Thus, it is evident that RR was reduced in response to more efficient ventilation, despite persistent elevated $\mathrm{PaCO}_{2}$ in these advanced COPD patients. These data are in agreement with a recent study of HFNC on patients presenting with acute respiratory failure, wherein, along with dyspnea, RR was significantly reduced compared to oxygen therapy via face mask. ${ }^{10}$

Braunlich and colleagues demonstrated similar ventilatory outcomes administering HFNC to severe, hospitalized COPD patients. ${ }^{12} \mathrm{RR}$ was reduced with HFNC, independent of flow rate above 20L/min, and despite a reduced minute volume hypercapnia, was reduced in a flow dependent manner with 20L/min and then 30L/min. These trials agree on the influence of $\mathrm{HFNC}$ on $\mathrm{CO}_{2}$ removal (ventilatory efficiency), however, the lack of reduction in $\mathrm{PaCO}_{2}$ or increase in $\mathrm{V}_{\mathrm{T}}$ in the current study may be attributed to the stability of the COPD patients evaluated here. Similarly, in a prior study by Braunlich and colleagues HFNC increased $\mathrm{V}_{\mathrm{T}}$ in hospitalized COPD patients, but not in healthy volunteers, which the authors reason is related to the need for the COPD patients to achieve more ventilatory work. ${ }^{13}$

In a study of COPD patients during rest and exercise with HFNC versus conventional oxygen therapy, Chatila and colleagues also compared oxygenation and ventilation indices. ${ }^{9}$ These authors compared low flow oxygen to HFNC at 20L/min wherein they controlled inspired oxygen fraction $\left(\mathrm{FIO}_{2}\right)$ by blending the HFNC gas composition to what would be reaching the lung in the low flow condition considering entrainment of room air during inhalation. Under these circumstances, the authors found that during both rest and exercise,
$\mathrm{PaO}_{2}$ and $\mathrm{SPO}_{2}$ were significantly improved with HFNC versus low flow oxygen, again with a decrease in RR. However, a critical difference in design of these 2 studies is that in the current study supplemental oxygen was not given with the HFNC condition. It is therefore likely that the reason why $\mathrm{PaO}_{2}$ during $\mathrm{HFNC}$ did not increase was due to the reduction in $\mathrm{RR}$, and therefore, in minute ventilation.

Recent studies of HFNC in adult in hypoxemic respiratory failure indicate that $\mathrm{HFNC}$ may be a more effective treatment for hypoxemia compared to noninvasive positive pressure ventilation. ${ }^{14,15}$ While these studies report positive outcomes for oxygenation support, they focused specifically on patients with stable ventilatory parameters and did not show differences in ventilatory indices; note, Stephan et al present $\mathrm{PaCO}_{2}$ and breathing frequency data without significant and clinically meaningful reductions. ${ }^{15}$ The current study shows a ventilatory effect, owing to a decreased minute ventilation without an effect on $\mathrm{PaCO}_{2}$, on patients with a consistent and stable oxygen response. Mechanistic evidence is suggesting that the ventilatory effect may be attributed to properties of the cannula, and subsequently the flow parameters. Frizzola and colleague showed in an animal model of respiratory failure that a cannula design optimizing the flush potential results in improved physiologic ventilation outcomes compared to a cannula that was more occlusive of the nares. ${ }^{6}$ Subsequent computation fluid modeling work demonstrated that cannula flow velocity plays a major role, in that greater velocity adds turbulent energy and accelerates the vortices formed on the nasal cavity. ${ }^{16}$ In this regard, the current trial was performed using the Vapotherm Flow Rest device platform that has a remarkably smaller cannula prong tip diameter compared to the Optiflow ${ }^{\mathrm{TM}}$ Cannulae (Fisher and Paykel Healthcare) used in the Frat and Stephan trials (FlowRest approximately=3.36 mm ID; adult Optiflow Cannula approximately=5.72 mm ID). ${ }^{14,15}$ This difference in cannula prong tip diameters results in a $189 \%$ difference, a 3 -fold increase, in exit flow velocity for the cannula used in this study (normalized to 30L/ min of volumetric flow typically used in this study: Flow rest approximately $=28.21 \mathrm{~m} / \mathrm{sec}$; Adult Optiflow approximately $9.75 \mathrm{~m} / \mathrm{sec}$ ). Therefore, at the lower flow rates used in the current trial compared to the large clinical evaluations, produced a much greater velocity and dynamic energy in the extrathoracic space. Cannula diameter was noted as $4.9 \mathrm{~mm}$ in the study by Braunlich 
and colleagues demonstrating a ventilation effect in COPD patients, ${ }^{12}$ but it is not specified whether this is the ID or OD. Nonetheless, the cannula ID is assumed to be in-between the dimensions discussed above.

HFNC may have provided a mild additional pressure in the upper airway, thus allowing for lower resistance in the upper airway and a lower respiratory rate. It is known from previous work that HFNC therapy can pressurize the upper airway up to $4 \mathrm{cmH} 20 .{ }^{9,17,18}$ In our study, we used a wide range of HFNC flow rates and saw benefits in patients who did not receive relatively high flows. Nonetheless, while the pressure effect may have been present it cannot explain discontinuity between minute ventilation and arterial blood gas values; i.e., ventilation decreased without a rise in $\mathrm{PaCO}_{2}$ or a fall in $\mathrm{PaO}_{2}$.

A limitation to this study in determining if HFNC can improve oxygenation in COPD patients is the time course of the protocol. It may be that $20 \mathrm{~min}$ is too short a time for HFNC to have an equilibration effect on oxygenation, as well as a downward trend in chronic hypercapnia. Another intriguing aspect of longer-term studies is the impact of ideally conditioned gas, as provided by HFNC systems, to improve mucocilliary clearance. Research is beginning to emerge suggesting a significant and clinically relevant improvement in mucocilliary function and secretion management. ${ }^{19,20}$
The present study was not designed to examine the effect of humidification on COPD patients.

In conclusion, our study does not support HFNC with room air as a successful stand-alone therapy for the purpose of oxygenating hypoxemic COPD patients who already require supplemental oxygen. However, HFNC therapy appears to improve respiratory efficiency through its effects on clearance of anatomic dead space $\mathrm{CO}_{2}$ and reductions in RR. Thus, HFNC therapy with small amounts of titrated oxygen may do more for COPD patients than supplemental oxygen alone, although this will require further study.

\section{Acknowledgements}

This study was sponsored by Vapotherm, Inc., Exeter, New Hampshire and conducted at the Veterans Administration Pittsburgh Healthcare System, Pittsburgh, Pennsylvania.

\section{Declaration of Interests}

Dr. Atwood received research funding from Vapotherm for this study. Dr. Camhi, Ms. Harwig, Dr. Paul, Mr. Schweikert have no disclosures. Mr. Macmillan is a former employee of Vapotherm. Dr. Miller is employed by Vapotherm. 


\section{References}

1. Dysart K, Miller TL, Wolfson MR, Shaffer TH. Research in high flow therapy: mechanisms of action. Resp Med.2009;103(10):14001405. doi: https://doi.org/10.1016/j.rmed.2009.04.007

2. Williams R, Rankin N, Smith T, Galler D, Seakins P. Relationship between the humidity and temperature of inspired gas and the function of the airway mucosa. Crit Care Med. 1996;24(11):19201929. doi: https://doi.org/10.1097/00003246-199611000-00025

3. Kelly MG, McGarvey LP, Heaney LG, Elborn JS. Nasal septal perforation and oxygen cannulae. Hosp Med. 2001;62 (4):248.

4. Kopelman AE, Holbert D. Use of oxygen cannulas in extremely low birthweight infants is associated with mucosal trauma and bleeding, and possibly with coagulase-negative staphylococcal sepsis. J Perinatol. 2003;23(2):94-97.

doi: https://doi.org/10.1038/sj.jp.7210865

5. Dewan NA, Bell CW. Effect of low flow and high flow oxygen delivery on exercise tolerance and sensation of dyspnea. A study comparing the transtracheal catheter and nasal prongs. Chest. 1994;105(4):1061-1065.

doi: https://doi.org/10.1378/chest.105.4.1061

6. Frizzola M, Miller TL, Rodriguez ME, et al. High-flow nasal cannula: impact on oxygenation and ventilation in an acute lung injury model. Pediatr Pulmonol. 2011;46(1):67-74.

doi: https://doi.org/10.1002/ppul.21326

7. Moller W, Celik G, Feng S, et al. Nasal high flow clears anatomical dead space in upper airway models. J Appl Physiol. 2015;118(12):1525-1532.

doi: https://doi.org/10.1152/japplphysiol.00934.2014

8. Calvano TP, Sill JM, Kemp KR, Chung KK. Use of a high-flow oxygen delivery system in a critically ill patient with dementia. Respir Care. 2008;53(12):1739-1743.

9. Chatila W, Nugent T, Vance G, Gaughan J, Criner GJ. The effects of high-flow vs low-flow oxygen on exercise in advanced obstructive airways disease. Chest. 2004;126(4):1108-1115. doi: https://doi.org/10.1378/chest.126.4.1108

10. Roca O, Riera J, Torres F, Masclans JR. High-flow oxygen therapy in acute respiratory failure. Respir Care. 2010;55(4):408413.

11. Parke RL, McGuinness SP, Eccleston ML. A preliminary randomized controlled trial to assess effectiveness of nasal high-flow oxygen in intensive care patients. Respir Care. 2011;56(3):265-270. doi: https://doi.org/10.4187/respcare.00801

12. Braunlich J, Kohler M, Wirtz H. Nasal highflow improves ventilation in patients with COPD. Int J Chron Obstruct Pulm Dis. 2016;11:1077-1085.

doi: https://doi.org/10.2147/COPD.S104616
13. Braunlich J, Beyer D, Mai D, Hammerschmidt S, Seyfarth HJ, Wirtz H. Effects of nasal high flow on ventilation in volunteers, COPD and idiopathic pulmonary fibrosis patients. Respiration. 2013;85(4):319-325.

doi: https://doi.org/10.1159/000342027

14. Frat JP, Thille AW, Mercat A, et al. High-flow oxygen through nasal cannula in acute hypoxemic respiratory failure. New Eng $J$ Med. 2015;372(23):2185-2196. doi: https://doi.org/10.1056/NEJMoa1503326

15. Stephan F, Barrucand B, Petit P, et al. High-flow nasal oxygen vs noninvasive positive airway pressure in hypoxemic patients after cardiothoracic surgery: A randomized clinical trial. JAMA. 2015;313(23):2331-2339.

doi: https://doi.org/10.1001/jama.2015.5213

16. Miller TL, Saberi B, Saberi S. Computational fluid dynamics modeling of extrathoracic airway flush: evaluation of high flow nasal cannula design elements. J Pulm Respir Med. 2016;6(5):376. doi: https://doi.org/10.4172/2161-105X.1000376

17. Parke R, McGuinness S, Eccleston M. Nasal high-flow therapy delivers low level positive airway pressure. $\mathrm{Br} J$ Anaesth. 2009;103(6):886-890. doi: https://doi.org/10.1093/bja/aep280

18. McGinley BM, Patil SP, Kirkness JP, Smith PL, Schwartz AR, Schneider H. A nasal cannula can be used to treat obstructive sleep apnea. Am J Respir Crit Care Med. 2007;176(2):194-200. doi: https://doi.org/10.1164/rccm.200609-13360C

19. Hasani A, Chapman TH, McCool D, Smith RE, Dilworth JP, Agnew JE. Domiciliary humidification improves lung mucociliary clearance in patients with bronchiectasis. Chron Respir Dis. 2008;5(2):81-86. doi: https://doi.org/10.1177/1479972307087190

20. Rea H, McAuley S, Jayaram L, et al. The clinical utility of longterm humidification therapy in chronic airway disease. Respir Med. 2010;104(4):525-533.

doi: https://doi.org/10.1016/j.rmed.2009.12.016 